\title{
Bone banking in a traumatologic department: A ten-year analysis
}

\author{
Vetter Sven Y., Raible Carsten, Aytac Sara, Grützner Paul Alfred, Frank Christian B.* \\ BG Trauma Center Ludwigshafen, Department for Trauma- and Reconstructive Surgery, Ludwig-Guttmannstr. 13, 67071 Ludwigshafen, \\ University of Heidelberg, Germany
}

Email address:

christian.b.frank@t-online.de (Frank C.B.)

\section{To cite this article:}

Vetter Sven Y., Raible Carsten, Aytac Sara, Grützner Paul Alfred, Frank Christian B.. Bone Banking in a Traumatologic Department: A TenYear Analysis. International Journal of Biomedical Materials Research. Vol. 2, No. 3, 2014, pp. 15-20.

doi: $10.11648 /$ j.ijbmr.20140203.11

\begin{abstract}
Background: Orthopedic and traumatologic departments have the choice of conducting an own bone bank in which grafts are prepared and stored, or purchasing costly bone grafts from professional providers. The aim of the study was to retrospectively analyse the bone bank affiliated with the traumatology department in the ten-year time period from 2001-2010. Patients and Methods: Altogether 1035 patients who underwent a primary hip replacement were included as potential donors. 632 patients were treated with a coxarthritis (CA) and 403 with a femoral neck fracture (FNF). Results: The bone donation was deferred in $731(70,6 \%)$ and conducted in $304(29,4 \%)$ patients. The majority of the deferrals were due to the maturity (age above 75 years) of the patients and an osteoporotic bone structure of the graft. Other reasons for deferral were a positive donor history, incomplete donation documents, and previous osteosynthesis of the proximal femur or acetabulum. The rate for exclusion was significantly higher in the FNF group, which was based on the difference of age, bone structure quality, and the non-elective setting of the operative treatment. Conclusion: In summary, bone donations from urgently hospitalised patients with a FNF have a significantly higher deferral rate than electively planned patients with CA.
\end{abstract}

Keywords: Bone Banking, Bone Graft, Bone Donation

\section{Introduction}

The transplantion of bone plays a key role within the orthopaedic and trauma surgery to meet the high demands of surgeons and patients for reconstruction of bone defects. The bone grafts are essential in the treatment of spacious skeletal defects during endoprosthetic or spinal procedures and arising from fractures, infections, and non-unions or after resections of bone tumors [1-6]. The first autologous bone donation was performed by the Scottish surgeon Macewen in Glasgow in 1881 [7]. Since then the indications and therapies for bone grafting have changed significantly.

The number of total knee and hip arthroplasties in Germany has significantly increased over the last decade. Since 2003 the amount of total hip arthroplasties rose by more than $20 \%$ and total knee replacements by more than $50 \%$. In consequence the revision rate has grown even more significantly, with $41 \%$ for hip and $117 \%$ for knee prostheses, and further increases in the total amount of joint replacements is expected in the following years due to demographic reasons [8]. This development will lead to an even more dramatic need for bone grafts to restore bonestocks for major implants.

The transplantation of autologous bone to cover defects is still considered to be the gold standard, and is preferred in comparison to allogenic grafts for its osteoconductive and osteoinductive effects. Autologous bone is routinely harvested from the anterior iliac crest for transplantation but is frequently not adequately available and presents with a prevalent donor site morbidity [9]. Therefore autologous bone transplantation is not always performed and allogenic grafts lacking in osteoinductive activity are instead used [1012] [13] [14]. While most of other donated tissue is obtained from cadaveric donors, bone grafts are typically attained as femoral heads from living donors during primary hip replacement [15]. The storage and transplantation of allogenic bone is well known and has been widely established since the first studies of Wilson in 1947 [16]. Allogenic grafts are stored and allocated by professional orthopaedic bone banks or regional solutions affiliated to a hospital. 
The efforts of these hospitals, especially in the highly specialised orthopaedic and trauma centers, to provide bone grafts are tremendous. In particular, the highly specialised orthopaedic and traumatologic centres transplanting regularly are affected. If a sufficient quantity of donated bone does not exist in stock, costly allogenic bone has to be purchased from professional providers, which carries the risk of reduced quality.

In conducting an individual bone bank, hospitals have to consider the complex management process [17]. A distinct process has to be initiated and multiple parameters have to be considered before performing a bone donation and transplantation (Fig. 1). Additionally the national law (i.e. in Germany $\S \S 20 \mathrm{~b}$ and $\mathrm{C}$ and 21 a of the German Pharmaceuticals Act) and the guidelines of the European Association of Musculo-Skeletal Transplantation (EAMST) have to be regarded.

Approximately 300.000 allogenic bone transplantations are performed in the U.S. and about 30.000 in Germany annually. In Germany the donated bone is processed by one of the 300 existing individual bone banks associated to a hospital [18], while in the U.S. the donor bone is prepared by a professional bone bank and is expensively acquired through the clinics. Differing in motivation, some hospitals have to purchase donor bone due to a lack of an own bone bank while others have to purchase bone grafts due to a quantity mismatch between bone donations and bone transplantations.

The aim of this study was to determine the deferral rate of feasible donations in a traumatology and orthopaedic department, and to elucidate reasons for exclusions. In addition structural improvement opportunities of bone donation were investigated.

\section{Material and Methods}

Potential bone donors and bone transplantations at our hospital were retrospectively analysed in the years 20012010 (Evidence Level III). The femoral head grafts were collected from living donors during primary hip arthroplasty according to the national law $(\S \S 20 \mathrm{~b}$ and $\mathrm{C}$ and $21 \mathrm{a}$ of the German Pharmaceuticals Act) [18 19] [20]. The operations were performed electively in case of arthritis or urgently in the event of femoral neck fractures. Depending on the necessity, urgent operations were carried out by the on-call duty team in the evening, at night, or on the weekend.

At first potential donors had to approve a possible bone donation during the total hip replacement in written form. Subsequent the patients were examined by a survey including questions to personal demeanours, previous illnesses and surgeries. A physical examination followed including the collection of blood samples.

During the hip arthroplasty the osteotomie of the femoral neck was accomplished in the typical manner with an oscillating saw. The femoral head was then removed with a corkscrew instrument and macroscopically inspected. In case of pathologic or suspicious findings, the graft was excluded
(Table 1). After removal the donor bone underwent a specific cycle of thermodisinfection. Primarily the hyaline cartilage of the femoral head was removed with a drill and the size of the remaining graft defined. Unless the size of the graft exceeded $56 \mathrm{~mm}$ in diameter the bone was bisected. The femoral head then was placed in a lobator container and immersed in saline solution. The thermodisinfection was promptly achieved by a minimal temperature of $82,5^{\circ} \mathrm{C}$ for 15 minutes during a heating periode of 90 minutes after the established standards of the University of Marburg and Telos [21] [22] [23]. After the cooling-off period the saline solution was attained under sterile conditions and aerobic and anaerobic microbiological tests were carried out. Until the transplantation the graft was cryoconserved at $-80^{\circ} \mathrm{C}$.

This practice leads to a safe bacterial and viral disinfection of the graft - a second HIV test is not essential - and additionally does not significantly change the integrity of the bone. In contrast to an autoclave method the thermodisinfection of the bone still contains $50-80 \%$ of its osteoinductive capacity and the osteoconductive effect is not impaired [24]. Simply cryoconserved grafts however have an unrestrained osteoinductive activity and no loss in the osseous structure but lack in antibacterial and antiviral safety compared to the thermodisinfected grafts. Dedicated bone bank nurses did not assist the process during the analysed period.

\section{Results}

From January 2001 to December 20101035 (425 male, 610 female) primary hip arthroplasties were performed. The mean age was 70,6 $\pm 12,9$ years (Fig. 2 and 3). Over the 10year period the number of primary hip arthroplasties per year increased insignificantly. Altogether 632 arthroplasties based on coxarthritis (321 male, 311 female) and 403 due to femoral neck fractures (104 male, 299 female) were performed.

A bone donation was conducted in 304 patients $(29,4 \%)$ and deferred in 731 patients (70,6 \%) (Fig. 4). Multiple reasons led to these results and to the apparently high deferral rate. In all 345 cases of donation the screening criteria were fulfilled. The femoral heads were macroscopically examined, prepared for a storage and regularly cryoconserved. Various donated grafts have already been transplanted to cover osseous defects.

39 patients $(4 \%)$ were excluded due to previous osteosyntheses of the femur or acetabulum. An incomplete questionnaire or serological examination was the reason for discarding $59(6 \%)$ grafts. The primary exclusion of 98 patients $(10 \%)$ was based on a positive donor history in the questionnaire due to already known diseases. A previous malignant disease was only relevant for a deferral of the graft in 38 patients (4\%). Many grafts (84) though were deferred intraoperatively $(8 \%)$ on account of various reasons. Numerous grafts were discarded either due to macroscopic findings after the removal or due to signs of osteoporosis in the preoperative $\mathrm{x}$-ray assessments. A necrosis of the femoral 
head lead to an exclusion of 16 patients $(2 \%)$. The age of the donor played the key role and constituted the exclusion of $417(40 \%)-255$ in the FNF and 162 in the CA group patients older than 75 years (Fig. 3).

44 out of 59 patients $(75 \%)$ with an incomplete questionnaire or serological examination who could not be included into the donation process were treated during oncall hours. This is demonstrated by the inclusion rate during on call shifts being significantly lower than during regular working hours. In addition 7 patients $(1 \%)$ refused a graft donation despite a detailed conversation (Fig. 5 and 6).

\section{Discussion}

Since the first bone transplantation by Macewen in Scotland the indications for a bone transplantation have changed considerably [7]. Until now the procedure of a bone donation has advanced and the bone donation is a standard procedure in orthopaedic surgery [25]. Bone transplantation to cover osseous defects is required frequently in endoprosthetic revision surgery. Therefore specialised departments rely on a peculiar bone bank or have to acquire costly prepared grafts from professional bone banks. Since bone donations are most commonly performed during an elective hip arthroplasty, departments with a high traumatolgic/orthopaedic patient ratio may develop a shortage of bone grafts for transplantation. In order to elucidate this challenge a ten-year analysis in a traumatologic/orthopaedic department was conducted.

The analysis of bone donation over a ten-year period reveals crucial data.

The investigation demonstrates that in this period about $60 \%$ of the patients were operated electively based on coxarthritis (CA) while in about $40 \%$ the hip arthroplasties were performed urgently due to femoral neck fractures (FNF). A standardised treatment of the patients in the FNF group was carried out including a contemporary surgical procedure. The data shows a significant decrease of bone donations in the FNF group in contrast to the CA group (21 donations vs. 324). In the FNF group only 21 patients were included in the process of bone donation in contrast to 403 potential donors. Multiple reasons appear to be responsible for these findings. The age of the two groups differed significantly revealing the maturity in the FNF group (mean $76,8 \pm 11,3$ years) in comparison to the CA group (mean 66,7 $\pm 12,9$ years). In addition the FNF group manifested with a higher rate of co-morbidities as reasons for exclusions. In addition almost all patients with a FNF were medicated by the emergency medical services before the hospitalisation. A premedication often led to an incomplete questionnaire or a missing written consent for a bone transplantation and consequently to an exclusion of the bone donation. In most cases $(71 \%)$ the indication for an urgent operation was posed during on-call services in the evening, at night, or on the weekends, which reduced the amount of possible donors due to a compromised preoperative treatment.
The importance of the human factor also has to be considered. In contrast to other facilities, bone bank nurses were not employed during the ten-year period and the required assignments were adopted by the doctors and nurses of the department [15] (Fig. 1). This possibly may have affected the number of donors being included into the donation process.

The intention of the installation of a bone bank adjacent to the hospital was to include as many donors as possible into the donation process to have a sufficient amount of bone grafts in stock, and to reduce the amount of purchased grafts from a professional bone bank. Analysing the data, more than two-thirds of all possible donors could not be included in a graft donation due to various reasons. Comparing the data published recently, between $56 \%$ [26] and 62,5\% [27] of the possible donation were deferred. The published cohort did not include urgent operations resulting from femoral neck fractures but consisted only from patients who were scheduled electively with coxarthritis. In addition the comparison of the published results is complicated due to differences of the criterions for exclusion.

It is the first time that data from a traumatologic department is analysed. The data demonstrates that in this population three possible donors are necessary to include one bone donor. This is especially based on multiple comorbidities and the maturity of the patients.

Even in orthopaedic departments with highly elective treatments bone donations are declined [28, 29].

Therefore, and with respect to data in the literature, the deferral rate in our retrospective study is less than expected; especially with regard to the high number of FNF that were submitted during on-call hours with limited manpower.

These numbers also may be due to the less critical requirements for a bone donation of the Marburg procedure in comparison to other methods[15] [27].

\section{Conclusion}

As a conclusion, it can be summarized that a lot of effort involving manpower has to be made to include a sufficient amount of donors. Urgently hospitalised patients with fractures of the femoral neck appear to be unsuitable for a bone donation due to many criterions for exclusion. Since a lot of bone grafts are yet necessary to fill osseous defects, traumatology and orthopaedic departments still have a vital concern to recruit large numbers of donations to cover their own demands. In departments with a disadvantageous donor/recipient ratio, additional bone from professional providers has to be purchased. The demographic changes in developed countries with an increasing number of revisions of arthroplasties will eventually require new concepts for bone banking.

We certify that there is no conflict of interest with any financial organization regarding the material discussed in the manuscript. 
Table 1. Criteria for an exclusion of a bone donation

\begin{tabular}{lll}
\hline Donor related reasons & Qualitiy related reasons & Other reasons \\
\hline Medication & Avascular necrosis of the femoral head & Missing documents \\
Systemic autoimmune disease, Infection & Previous surgery of the hip joint & Emergency surgery \\
History of malignancy & Size & Untrained personal \\
$\begin{array}{l}\text { Dementia/M.Parkinson/CJD/ Other mental illness } \\
\text { Travel-/Social-/Behavioural history }\end{array}$ & & \\
\hline
\end{tabular}

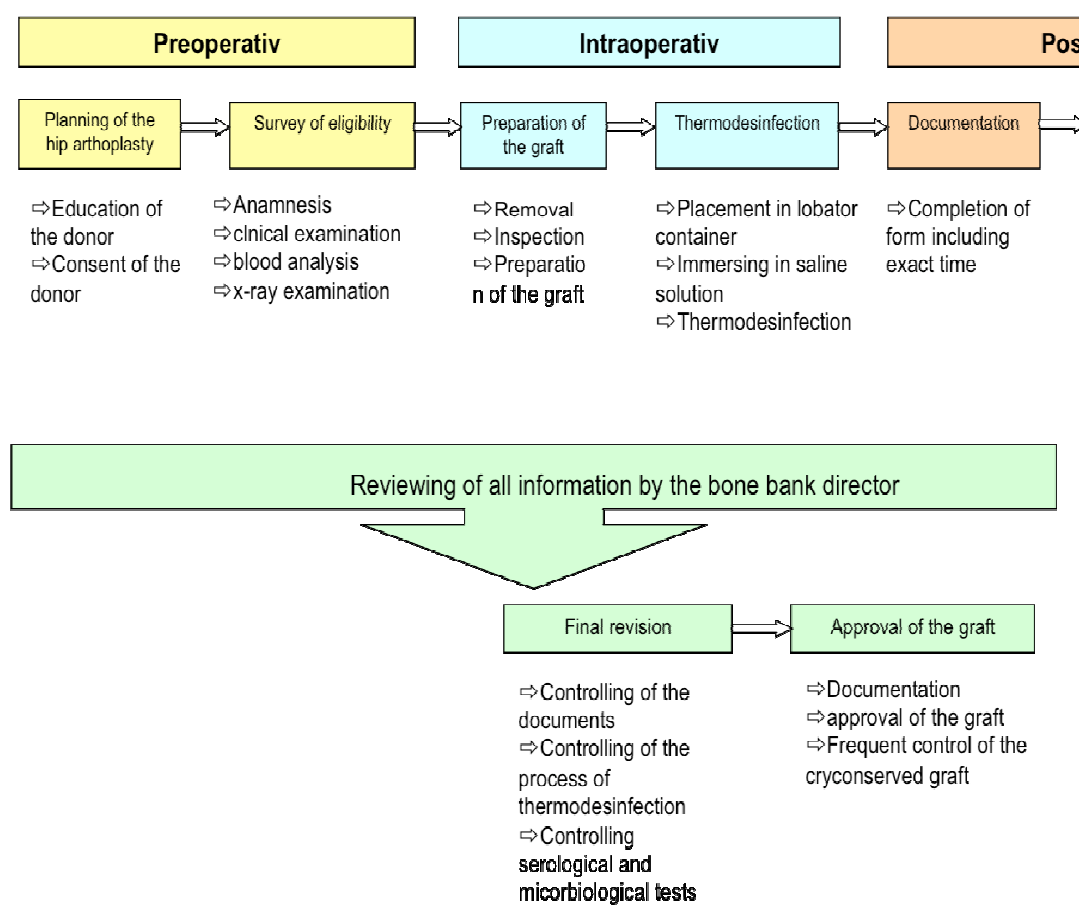

Figure 1. Process of an elective bone donation in the hospital.

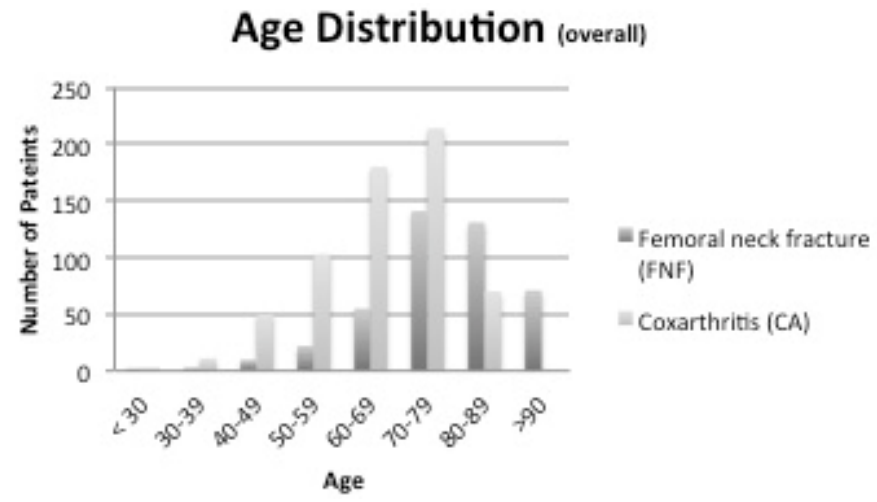

Figure 2.Overall age distribution of the bone donors in years.

\section{Age distribution in groups}

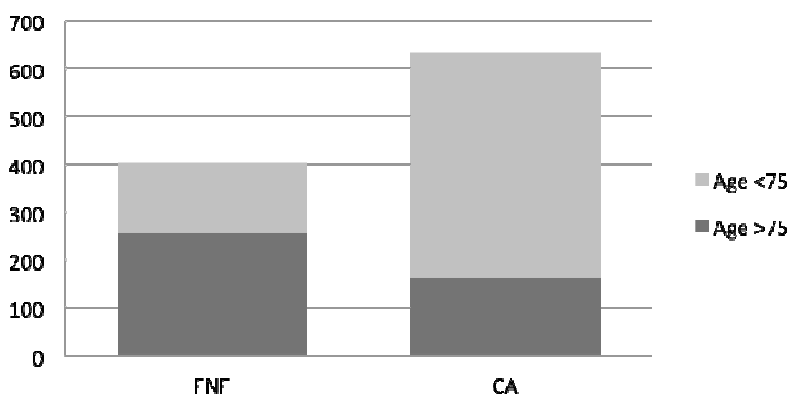

Figure 3. Age distribution of the bone donor groups in years. 


\section{Bone donation (overall)}

Bone donation $\square$ Deferral

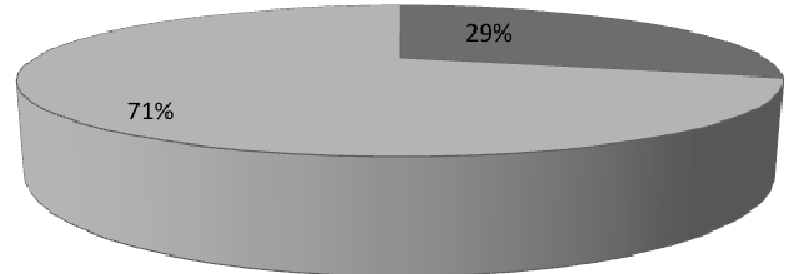

Figure 4. Percentage of the bone donation and bone donor deferral overall.

\section{Reasons for deferral}

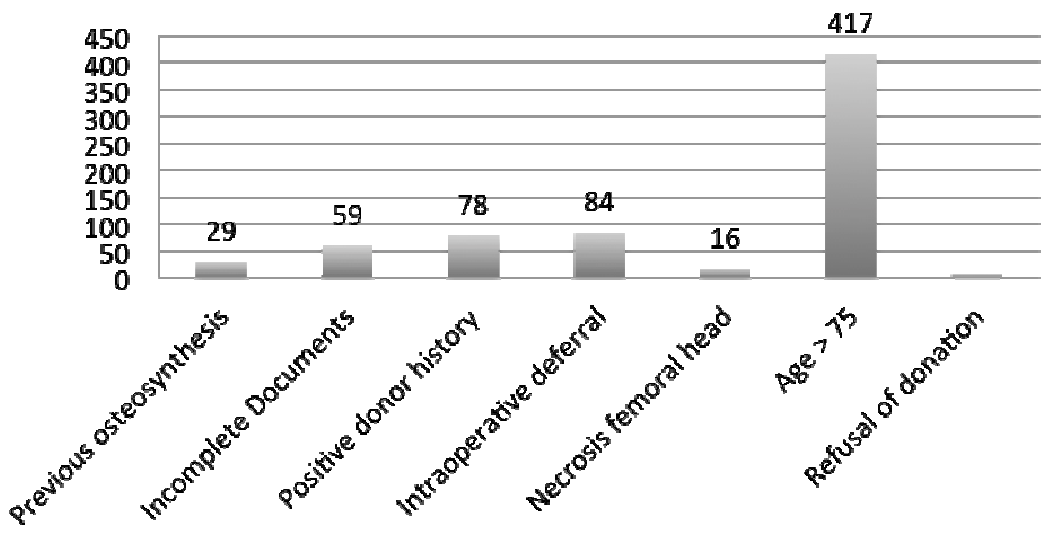

Figure 5. Total number of deferrals in relation to the deferral reason.

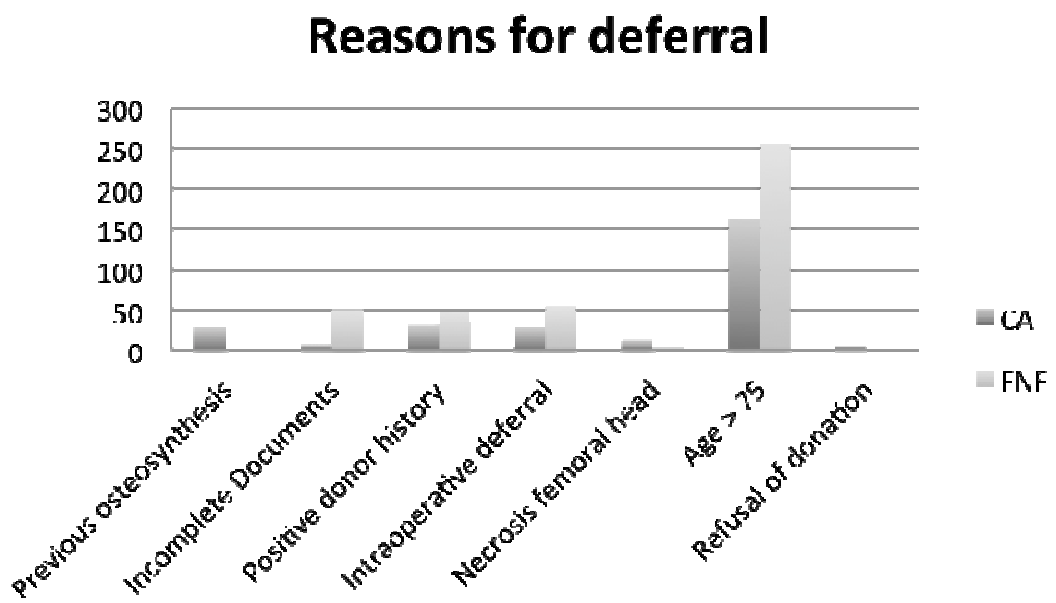

Figure 6. Number of deferrals in relation to the reason and groups.

\section{References}

[1] Gamradt S, Liebermann J. Bone graft for hip arthorplasty; biology and future applications. Clinical Orthopedics 2003;417:183-94

[2] Stevenson S. Enhancement of fracture healing with autogenous and allogenic bone grafts. Clin Orthop Rel Res 1998;355:239-46

[3] Friedlaender G. Bone grafts. The basic science rationale for clinical applications. J Bone Joint Surg Am 1987;69:786-90

[4] Mankin H, Gebhardt M, Jennings L, et al. Long-term results of allograft replacement on the management of bone tumors. Clin Orthop Relat Res 1996;324:86-97

[5] Raizmann N, O'Brien J, Poehling-Monaghan K, et al. Pseudarthrosis of the spine. J Am Acad Orthop Surg 2009; $17: 494-503$

[6] Slooff T, Buma P, Schreurs B, et al. Acetabular and femoral reconstruction with impacted graft and cement. Clin Orthop Relat Res 1996;324:108-15 
[7] Macewen W. Observations concerning transplation on bone. Proc R Soc London 1881;32:232-46

[8] Robertsson O, Stefánsdóttir, A; Lidgren, L; Ranstam, J. Increased long-term mortality in patients less than 55 years old who have undergone knee replacement for osteoarthritis. J Bone and Joint Surg Br 2007;89:599 - 603

[9] Summers B, Eisenstein S. Donor site pain from the ilium. A complication of lumbar spine fusion. J Bone Joint Surg Br 1989;71:677-80

[10] Elves M, Pratt L. The pattern of new bone formation in isografts of bone. Acta Orthopedic Scandinavia 1975;46:54960

[11] Urist M. Physiologic basis of bone-graft surgery; with special reference to the theory of induction. Clin Orthop Relat Res $1953 ; 1: 207-16$

[12] Bauer T, Mutschler G. Bone graft materials: An overview of the basic science. Clin Orthop Rel Res 2000;371:10-27

[13] Palmer S, Gibbons C, Athansou N. The pathology of bone allograft. J Bone Joint Surg Br 1999;81:333-35

[14] Sugihara S, van Ginkel A, Jiya T, et al. Histopathology of retrieved allografts of the femoral head. J Bone Joint Surg Br 1999;81:336-41

[15] Galea G. An analysis of bone donor deferral rates in Scotland - a 6-year study. Transfusion Medicine an Hemotherapy 2011;38:373-78

[16] Wilson P. Experiences with a bone bank. Annutation Surgery 1947;126(6):932-46

[17] Zwitser E, Jiya T, Licher H, et al. Design and management of an orthopedic bone bank in the Netherlands. Cell Tissue Bank 2010;13:63-69

[18] Pruss A, Katthagen B. Musculosceletal tissue banks. Legal foundations and graft safety. Orthopäde 2008;37:749-55
[19] Bettin D, Doerr H, Gerlich W. Richtlinien zum Führen einer Knochenbank. Deutsches Ärzteblatt 2001;98:1011-16

[20] Verdonk R, Almquist K, Verdonk P. Logistics and European laws on allogenic tissue transplantation. Orthopäde 2008;37:779-82

[21] Knaepler H, von Garrel T, Seipp H, et al. Experimental studies of thermal disinfection and sterilization of allogenic bone transplants and their effects on biological viability. Unfallchirurg 1992;95:477-84

[22] Matter H, Garrel T, Bilderbeek U, et al. Biomechanical examinations of cancellous bone concerning the influence of duration and temperature of cryopreservation. J Biomed Mater Res 2001;55:40-44

[23] Pruss A, Seibold M, Benedix F. Validation of the "Marburg bone bank system" for thermodesinfection of allogenic femoral head transplants using selected bacteria, fungi and spores. Biologicals 2003;31:287-94

[24] V. Garell T, Gotzen L. Allogenic bone transplantation and bone banking. Unfallchirurg 1998;101:713-27

[25] Tomford W, Mankin H, Friedlaender G, et al. Methods of banking bone and cartilage for allograft transplantations. Orthop Clin North Am 1987;18:241-47

[26] Flören M, Kappe T, Reichel H. Analysis of the effectiveness of an internal hospital bone bank. Orthopäde 2007;36:667-72

[27] Pink F, Warwick R, Purkis J, et al. Donor exclusion in the national blood services living bone donor programme. Cell Tissue Bank 2006;7:11-21

[28] Jung S, Wernerus D, Reichel H. Approval of a bone bank: an institution's experience. Orthopade 2012; 41: 217-224

[29] Benninger E ZP, Kamath AF, Dora C. Cost analysis of freshfrozen femoral head allografts: is it worthwhile to run a bone bank? Bone Joint J 2014; 96-B(10): 1307-1311 